\title{
Effects of Cerium Oxide Nano Particles Addition in Diesel and Bio Diesel on the Performance and Emission Analysis of CI Engine
}

\author{
K.Srinivasa Rao ${ }^{1}$, B.L.V.S.Gupta ${ }^{2}$, K.Mallikarjuna Rao ${ }^{3}$, G.Sambasiva Rao ${ }^{4}$ \\ ${ }^{I}$ M.Tech Student, Thermal engineering, V.R Siddhartha Engineering College, JNTU \\ ${ }^{2}$ Assistant Professor, Mechanical Engineering, V.R Siddhartha Engineering College, JNTU \\ ${ }^{3}$ Professor, Mechanical Engineering, Jawaharlal Nehru Technological University, JNTUK \\ ${ }^{4}$ Professor \& Principal, Mechanical Engineering, Sir C.R.Reddy College Of Engineering, Andhra University \\ Andhra Pradesh, India
}

\begin{abstract}
An experimental investigation is carried out to establish the performance and emission characteristics of a compression ignition engine while using cerium oxide nanoparticles as additive in neat diesel and diesel-biodiesel. In the first phase of the experiments, stability of neat diesel and diesel-biodiesel blends with the addition of cerium oxide nanoparticles are analyzed. After series of experiments, it is found that the blends subjected to high speed blending followed by ultrasonic bath stabilization improves the stability. In the second phase, performance characteristics are studied using the stable fuel blends in a single cylinder four stroke engine. The cerium oxide acts as an oxygen donating catalyst and provides oxygen for the oxidation of $\mathrm{CO}$ or absorbs oxygen for the reduction of NOx. The activation energy of cerium oxide acts to burn off carbon deposits within the engine cylinder at the wall temperature and prevents the deposition of non-polar compounds on the cylinder wall results reduction in $\mathrm{HC}$ emissions. The tests revealed that cerium oxide nanoparticles can be used as additive in diesel and diesel-biodiesel to improve complete combustion of the fuel and reduce the exhaust emissions significantly.
\end{abstract}

Keywords - Bio fuels, Cerium Oxide, engine performance and emissions.

\section{INTRODUCTION}

The compression ignition engines are widely used due to its reliable operation and economy. Due to the shortage of petroleum products and its increasing cost, efforts are on to develop alternative fuels especially for diesel oil for its partial replacement. Ever increasing fuel price, continuous addition of on road vehicles, fast depleting petroleum resources and continuing accumulation greenhouse gases are the main reasons for the development of alternative fuels. Many alternative fuels are identified and tested successfully in the existing engine with and without engine modification. However, research is still continuing in this field to find the best alternative fuel for the existing petro fuel.

Most of the alternative fuels identified today are bio-fuels and are having one or few undesirable fuel characteristics which are not permitting them to replace the existing petro fuel completely. However, the various admission techniques experimented by the researchers are giving good solution to apply larger fraction of replacing fuel in the existing engine.
The automobile pollution constitutes about $70 \%$ of total pollution. The products of combustion when a hydro carbon fuels are burnt in the presence of oxygen are un burnt $\mathrm{HC}$, $\mathrm{NO}_{\mathrm{X}}, \mathrm{CO} \mathrm{CO}_{2}$, and $\mathrm{H}_{2}$. These cause several disasters. Human beings are immediate victims. This pollution causes to suffer from headache, dizziness, eye irritation, brain damage, cancer, kidney damage etc.Further Rising fuel costs and impending emissions regulations have sharpened the automotive industry's focus on efficiency. In search for alternative fuels, the favourable option was found to be renewable fuels like vegetable oils, alcohol etc.The various edible vegetable oils like sunflower, soybean, peanut, cotton seed etc have been tested successfully in the diesel engine. Research in this direction with edible oils yielded encouraging results. Diesel is produced from crude oil, biodiesel is produced from vegetable oils, and either edible or non edible oils can be used depending on their properties.

Using straight vegetable oils as a fuel substitute an option but only with many modifications to be performed on the engine itself for continued satisfactory engine performance. In future more advanced engines may be designed to cope with these crude oils. However at the current time and for a transition period to a cleaner fuel system biodiesel is a viable option. To allow the use of vegetable oils as a fuel without modification of the engine, the fuel needs to be modified for compatibility with the engine. As the diesel engines are designed for diesel fuel any substitute needs to have similar properties for the engine to operate satisfactorily. Biodiesel is a viable opportunity that will not incur large costs for a new infrastructure as the storage and distribution will be the same as the diesel infrastructure.

Biodiesel fuel blends are one option currently being researched as a pathway to energy diversity and reduced petroleum dependence in the transportation sector. It has found that addition of nano particles in bio diesel further improve the performance of C.I engine. They act as effective catalyst when added to the diesel and bio diesel blends. Thus provides oxygen for complete combustion of fuel.

\section{LITERATURE SURVEY}

POOLA R.B.et al [1] carried out an experiment in the year 1993 with $20 \%$ by volume of orange oil and eucalyptus oil were separately blended with gasoline brake thermal 
efficiency, exhaust emissions and combustion parameters were obtained. The experiment was conducted on small capacity loop scavenged, air cooled, single cylinder, two stroke ignition engines with a compression ratio of 7.4. it was found that the performance fuel blends was better than gasoline fuel. Experiment was performed on two compression ratios which are 7.4 and 9 and improvement of $20.5 \%$ in brake thermal efficiency was obtained at $2 \mathrm{kw}$, $3000 \mathrm{rpm}$ over normal gasoline engine.

PURUSHOTAMAN et al. [2] Have evaluated the performance, emission and combustion characteristics of a single cylinder, constant speed, direct injection diesel engine using orange oil as an alternative fuel. The results are compared with the standard diesel fuel operation. The results indicated that the brake thermal efficiency was higher compared to diesel. $\mathrm{CO}$ and $\mathrm{HC}$ emissions were lower and oxides of nitrogen were higher compared to diesel operation.

TAMILVENDHAN.D et al.[3] carried out the experimental study on the performance, emission characteristics of a methyl ester sunflower oil, eucalyptus oil on a single cylinder air cooled and direct injection diesel engine as an alternative fuel and the results which were obtained in the test are compared with the results of standard diesel fuel. When eucalyptus oil having low cetane number is mixed with methyl ester sunflower oil having high cetane number up to $50 \%$ increase in brake thermal efficiency up to 2 to 3 percentage.

M.SENTHIL KUMAR et al [4] carried out experiment on the use of vegetable directly in compression ignition engines. Along with that small quantities of orange oil were inducted along with air and ignited after compression. Methyl ester of jatropha oil and diesel were also used as fuels for comparing the results with results with that of the vegetable oil.

DEVAN P K et al.[5] worked on to find out the performance, emission and combustion characteristics of diesel engine using poon oil based fuels and poon oil and poon oil methyl ester are tested in blended forms they prepared in blend with $20 \%$ poon oil and $40 \%$ poon oil methyl ester separately with standard diesel. Resulted obtained show the reduction of $\mathrm{CO}$ and $\mathrm{HC}$ emissions.

Gopalkrishnan et al. [6] have reported that the performance of some vegetable oils and methyl esters of some vegetable oils. The vegetable oils tested were karanji oil (Pongamia glabra), rice bran oil and palm oil on a single cylinder diesel engine. In the second phase tests were conducted with methyl esters of karanji oil, soybean oil, sunflower oil, rapeseed oil and neem oil. The results of the tests are discussed with reference to the thermal efficiency, combustion parameters like delay period, combustion duration and peak pressure and smoke emission.

\section{Bio Diesel Production Process}

The chemical process commonly used make bio-oils less viscous, turning them into "biodiesel" is called "Transesterification" [8].

\section{A. Transesterification Process}

Eucalyptus oil was used as the raw oil to be transesterified with methanol in a reacting tank. The temperature values are below the boiling point of methanol $\left(63^{\circ} \mathrm{C}\right)$, to prevent the methanol in the reactant mixture from evaporating [9].

The potassium hydroxide was stirred with methanol for 10 minutes using an electric-magnetic stirrer to form potassium methoxide, which was then poured into the reacting tank and mixed with the hibiscus oil [10]. The total reaction time was 60 minutes. Almost total conversion to hibiscus oil bio diesel was achieved quickly after a few minutes from the start of the reaction, depending on the ambient conditions.

The chemical formula for biodiesel Transesterification is:

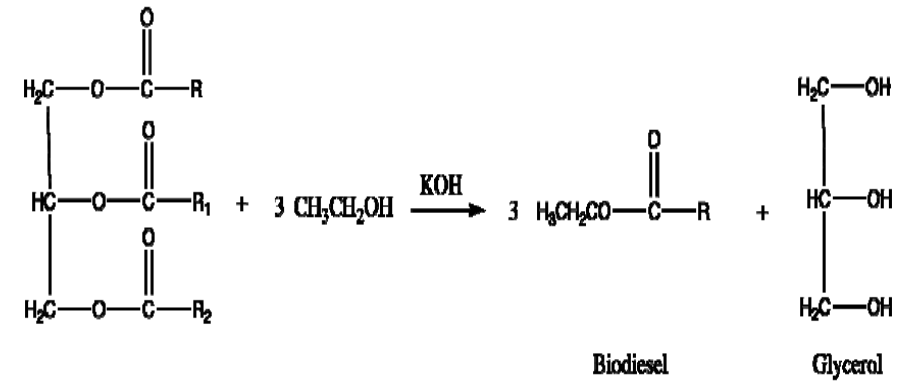

\section{B. Properties of biodiesel comparison with diesel}

\begin{tabular}{|c|c|c|}
\hline Properties & Eucalyptus oil & Pure diesel \\
\hline $\begin{array}{c}\text { Density at } 15^{0} \mathrm{c} \\
\left(\mathrm{kg} / \mathrm{m}^{3}\right)\end{array}$ & 913 & $820-950$ \\
\hline $\begin{array}{c}\text { Viscosity at } 40^{0} \mathrm{c} \\
(\text { Centi stokes })\end{array}$ & 2 & 3 \\
\hline $\begin{array}{c}\text { Flash point } \\
\left({ }^{0} \mathrm{C}\right)\end{array}$ & 53 & 57 \\
\hline $\begin{array}{c}\text { Fire point } \\
\left({ }^{0} \mathrm{C}\right)\end{array}$ & 0.918 & $0.82-0.95$ \\
\hline $\begin{array}{c}\text { Specific Gravity } \\
\text { Calorific value } \\
(\mathrm{KJ} / \mathrm{kg})\end{array}$ & 43,270 & 42,500 \\
\hline
\end{tabular}

\section{EXPERIMENTAL INVESTIGATION}

The experiment was conducted on a single cylinder four stroke diesel engine.

\section{A. Description of test rig}

The brake drum is directly coupled to the engine flywheel and a rope brake wounded around the drum. Top end of the rope is 
connected to a spring balance and bottom end of the rope is connected to weighing platform. The load to the engine can be varied by adding slotted weights provided on to the platform.

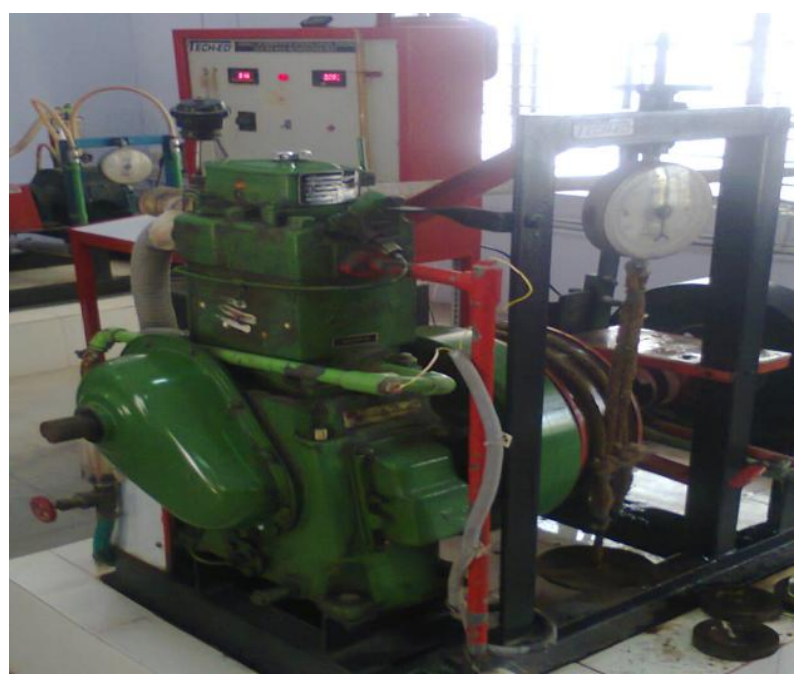

Fig: four stroke single cylinder diesel engine.

\section{B. Test engine specifications}

TABLE I

\begin{tabular}{|c|c|}
\hline Engine & Four stroke single cylinder \\
\hline BHP & $5 \mathrm{HP}$ \\
\hline RPM & 1500 \\
\hline Fuel & Diesel \\
\hline Number of cylinders & Single \\
\hline Bore & $80 \mathrm{~mm}$ \\
\hline Stroke & $110 \mathrm{~mm}$ \\
\hline Starting & Manual cranking \\
\hline Working cycle & Four stroke \\
\hline Method of cooling & Water cooled \\
\hline
\end{tabular}

\section{Test methodology}

The diesel taken in a empty burette and connect the waterline to the engine socket and brake drum. The engine is started manually and allows it to stabilize at its rated speed (1500 RPM). Now load the engine in steps of $2 \mathrm{~kg}, 4 \mathrm{~kg}, 6 \mathrm{~kg} .8 \mathrm{~kg}$, $10 \mathrm{~kg}$ and allow the engine to stabilize at each load.

Time taken for consumption of $5 \mathrm{cc}$ fuel and speed of the engine are measured with the help of different sensors mounted on digital panel. The process parameters such as brake power, specific fuel consumption are measured.

$10 \%$ eucalyptus oil is taken in flask and blended with $90 \%$ diesel by volume. The diesel should be at the bottom of flask and the eucalyptus oil should be poured at top diesel otherwise bio fuel does not mix completely with the diesel. This mixture is intourduced into the engine and the corresponding readings are taken.

The same procedure repeated with $20 \%$ eucalyptus oil+80\% diesel, $30 \%$ eucalyptus oil $+70 \%$ diesel, $10 \%$ eucalyptus oil $+90 \%$ diesel+20 ppm $\mathrm{CEO}_{2}, 20 \%$ eucalyptus oil+80\% diesel+40 ppm $\mathrm{CEO}_{2}, 30 \%$ eucalyptus oil+70\% diesel+60 ppm $\mathrm{CEO}_{2}$ and the corresponding readings are taken.

\section{Results and discussions}

\section{Performance characteristics:}

Fig.1 shows the variation of specific fuel consumption with respect to load From the below graph we can analyze that, specific fuel consumption goes on decreasing upto full load and $\mathrm{B} 20+40 \mathrm{ppm} \mathrm{CeO}_{2}$ blend gives lower specific fuel consumption value compared to other. Hence B20+40 ppm $\mathrm{CeO}_{2}$ is a better option.

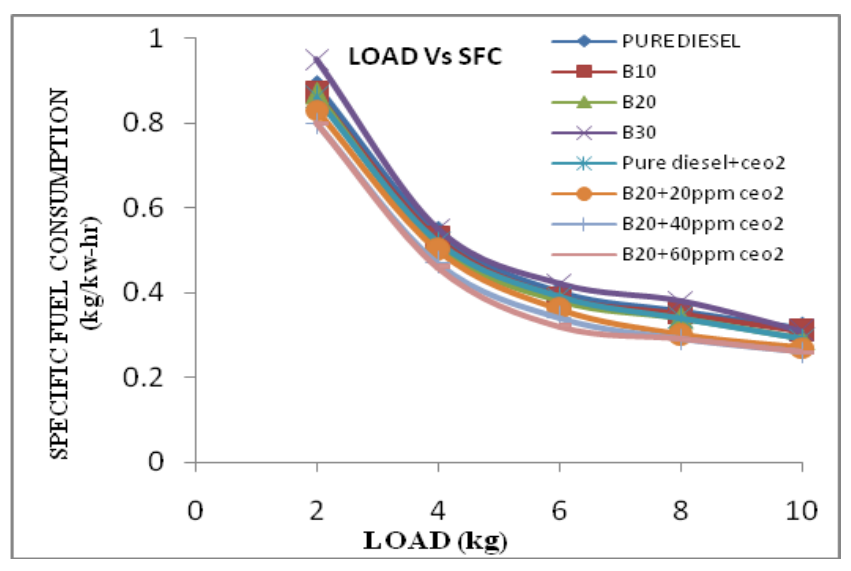

Fig.1 Specific fuel consumption against Load

Fig. 2 shows the variation of volumetric efficiency with respect to load. With the increase in load the volumetric efficiency also increased.

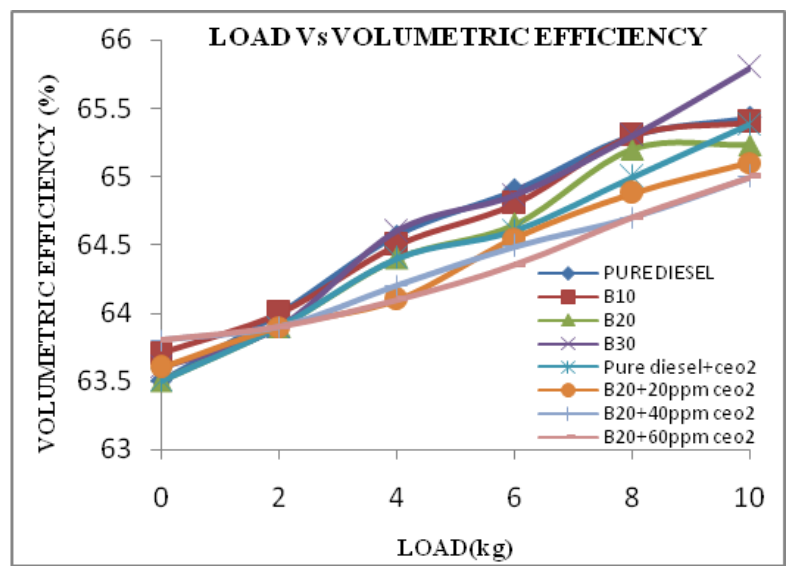

Fig.2 Volumetric efficiency against Load 
Fig.3 shows the variation of brake thermal efficiency with respect to load With the increase in loads the brake thermal efficiency increased gradually this may be due to complete combustion of the fuel in the combustion chamber and the quality of fuel spray.

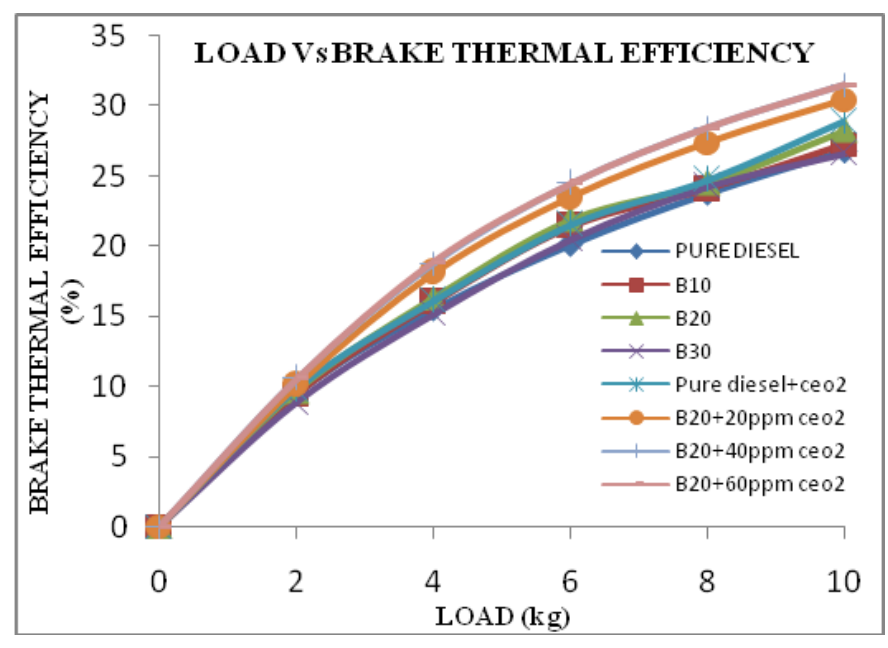

Fig.3 Brake thermal efficiency against Load

\section{Emission Characteristics}

Fig.4 shows the variation of carbon monoxide with load $\mathrm{CO}$ emission of eucalyptus oil blends with various loads. At low and medium loads, CO emissions of the blends were not much difference from std.diesel fuel operation. The CO emission of eucalyptus oil blends decreased significantly at full load. This may be due to the enrichment of oxygen in the eucalyptus oil addition, $\mathrm{CeO}_{2}$ in which an increase in the proportion of oxygen promotes further oxidation of $\mathrm{CO}$ during the engine exhaust process.

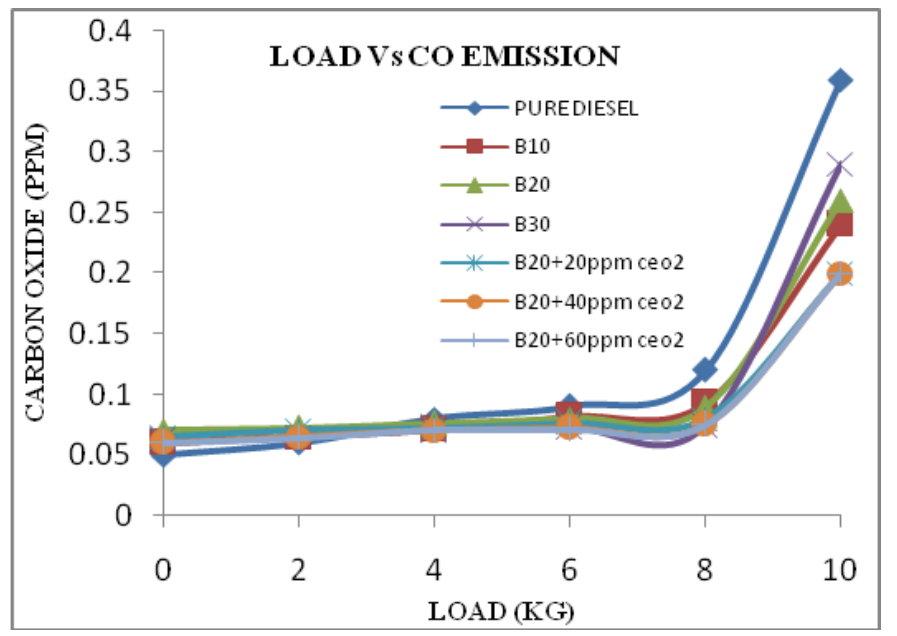

Fig.4 Carbon monoxide against Load

Fig. 5 shows the variation of hydro carbon with load variation of $\mathrm{HC}$ emission of eucalyptus oil blends fuel under various engine load. The HC level reduces with increase in load for diesel as well as blends. The HC emissions are lower than that of diesel fuel, and this may be due to complete combustion.

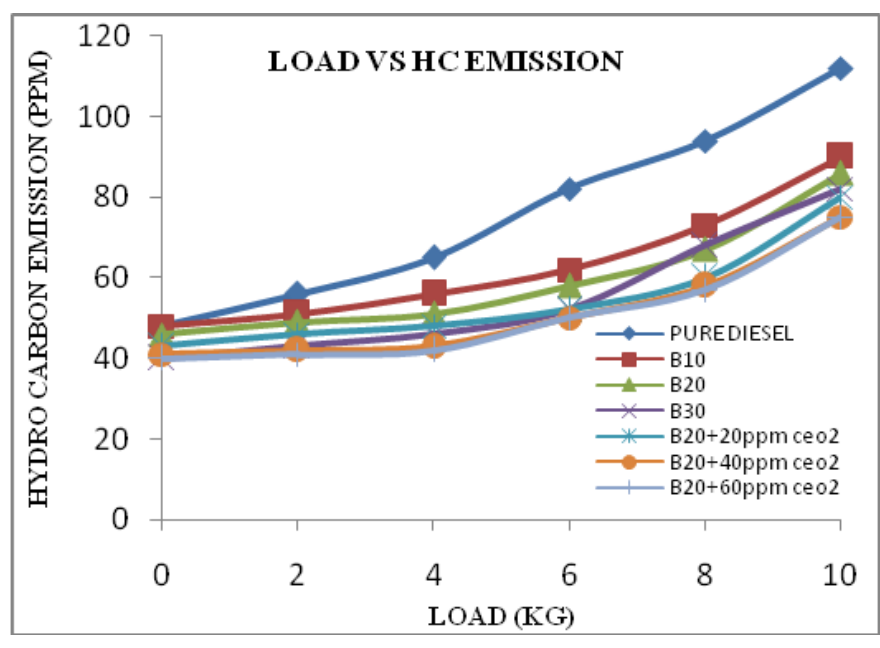

Fig.5 Hydro carbon against Load

Fig. 6 shows the variation of nitrogen oxide with load variation of $\mathrm{NO}_{\mathrm{x}}$ emission for eucalyptus oil blends and standard. diesel for different engine load. The increase in trend may be due to the presence of oxygen in eucalyptus oil. Many researchers reported that oxygenate fuel blends can cause an increase in $\mathrm{NO}_{\mathrm{x}}$ emission. Normally complete combustion causes higher combustion temperature which results in higher $\mathrm{NO}_{\mathrm{x}}$ formation. Another reason for the increase in NOx emission is the cetane suppressing property of eucalyptus oil. Usually, low cetane fuels offer longer ignition delay and release more heat during the premixed phase of combustion.

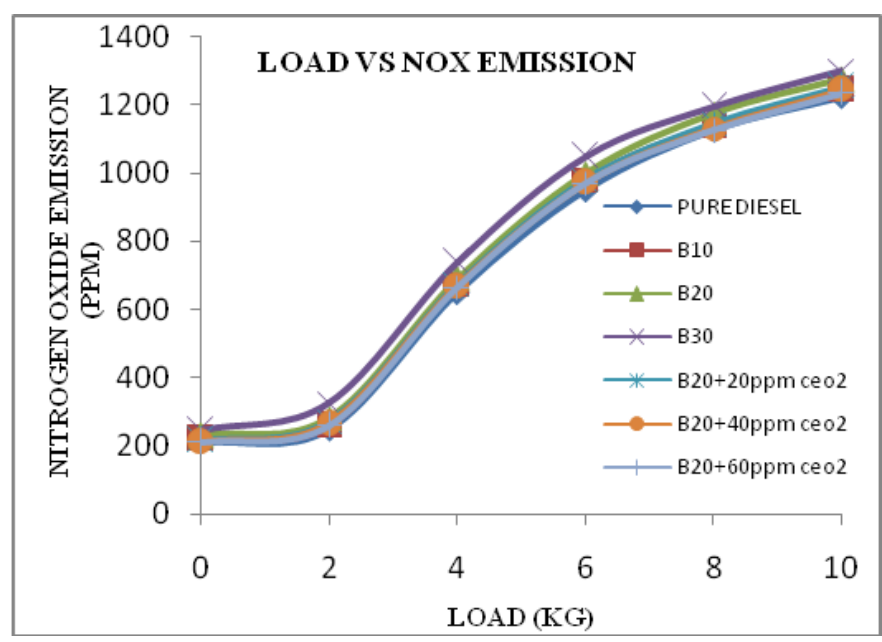

Fig.6 Nitrogen oxide against Load

\section{Conclusions}

The performance and emission characteristics of diesel and bio diesel with nano particles as additive were investigated on 
four stroke single cylinder vertical water cooled diesel engine. The conclusions of this investigating at are as follows.

1. Brake thermal efficiency has been improved by using B20 blends with addition of cerium oxide nano particles.

2. Specific fuel consumption is found to decrease as load increases. At full load the lowest specific fuel consumption is found to be $0.268 \mathrm{~kg} / \mathrm{kw} \mathrm{hr}$.

3. The improvement in the brake thermal efficiency and specific fuel consumption may be because of eucalyptus oil, which is high volatile basically consists of cineole as the major component. It decomposes easily at low temperature due to that it releases more intermediate components immediately after its injection.

4. Increased volatility and reduced viscosity are the benefits of these blends, which led to fine atomization and better spray formation.

5. The added advantage of this eucalyptus oil is that, it can be blended with any oil without any modification.

6. It is understood that cerium oxide being thermally stable promotes the oxidation, thus acting as an effective catalyst, when added in the

7. nano particle form.

8. Addition of cerium oxide nano particles increases the engine performance when added in the quantity of 40 ppm to B20 blends.

9. Oxygenated fuel blends can cause an increase in NOx emission normally complete combustion temperature which results in higher $\mathrm{NO}_{\mathrm{X}}$ formation.

10. The $\mathrm{CO}$ emission of eucalyptus oil blends decreased significantly at full load with addition of $\mathrm{ceo}_{2}$.

\section{REFERENCES}

1. Ramesh B. Poola, Nagalingam B and Gopalakrishnan K.V(1994), 'performance studies with bio mass derived high octane fuel additives in two stroke spark ignition engines', biomass and bio energy 6(5),369-379

2. K.Purushotaman and G.Nagarajan (2009), 'performance, emission and combustion characteristics of a compression ignition engines operating on orange oil renewable energy' volume 34 , pages $242-245$

3. Tamilavandhan. D, Itlangovan, performance emission and combustion characteristics of a methyl ester sun flower oil eucalyptus oil in a single cylinder air cooled and direct injection diesel engines, ISSN : 0975-5462, Vol.3 no.3 march 2011.

4. Senthil kumar M, Ramesh A and Nagalingam B (2001) . complete vegetable oil fueled dual fuel compression ignition engine ,SAE international 28-0067, p.441-448

5. P.K.Devan and N.V. Mahalakshmi (2009), 'study of the performance, emission characteristics of a diesel using poon oil blends' fuel processing technology 90 513-519

6. P.S.Rao, K.V. Gopalkrishnan. Vegetable oils and their methyl esters as fuels for diesel engines. Indian Journal of Technology Vol. 29 June 1991 pp. 292-297.

7. J.Zubik, S.C.Sorenson and C.E.Goering (1984). 'diesel engine combustion sunflower oil fuels', trans ASAE 27(5), pp.1252-1256

8. P.K.Devan and N.V. Mahalakshmi (2009), 'study of the performance, emission characteristics of a diesel using poon oil blends' fuel processing technology 90 513-519

9. P.K.Devan and N.V.Mahalakshmi (2009) 'a study of the performance,emission and combustion characteristics of a compression ignition engine using methyl ester of eucalyptus oil blends' Appied energy 86675A

10. Hollman JP (2003) ,'Experimental techniques', Tata McGraw Hill Publications .

11. Devan P.K. and N.V.Mahalakshmi 2010 'combustion, emission and performance characteristics of diesel engine fueled with eucalyptus oil with an ignition enhancer. International journal of green energy and environment 40-49. 